\title{
COVID-19 Pandemic Response in Japan: What Is behind the Initial Flattening of the Curve?
}

\author{
Ai Tashiro ${ }^{1(\mathbb{C})}$ and Rajib Shaw ${ }^{2, *(\mathbb{D})}$ \\ 1 Graduate School of Environmental Studies, Tohoku University, 468-1 Aoba, Aramaki, Aoba-ku, Sendai, \\ Miyagi 980-0845, Japan; ai.tashiro.q7@dc.tohoku.ac.jp \\ 2 Graduate School of Media and Governance, Faculty of Policy Management, Keio University, 5322 Endo, \\ Fujisawa-hi, Kanagawa 252-0882, Japan \\ * Correspondence: shaw@sfc.keio.ac.jp
}

Received: 15 May 2020; Accepted: 27 June 2020; Published: 28 June 2020

\begin{abstract}
The new coronavirus disease (COVID-19) emerged in December 2019 and became a global pandemic in March 2020. The unprecedented speed of SARS-CoV2 spread, the high infection rate among the aged population, and the collapse of healthcare systems in several countries have made COVID-19 the worst "modern" pandemic. Despite its proximity to China, a large aged population, and a high urban density, Japan has mitigated successfully the initial catastrophic impacts of COVID-19. This paper analyzed the key policy measures undertaken in Japan and suggests that Japan's culture, healthcare system, sanitation, immunity, and food habits, along with citizens' behavior, are the possible reasons for the successful flattening of the curve. Although additional disease peaks may occur, and a consequent increase in the number of affected individuals, a combination of policy, good governance, a healthy society, and good citizen behaviors' should be sufficient to provide enough time for the health care system to cope with them. Cluster approach, science-based decision making, and scenario planning were some of the key policy decisions taken by the government. Based on the lessons from Japan, this paper suggests the importance of an ecosystem-based lifestyle as a potential way to cope with pandemic events.
\end{abstract}

Keywords: cluster approach; scenario planning; expert advice; ecosystem approach; $3 \mathrm{C}$ approach (closed space; crowded space; close contact setting)

\section{Introduction}

More than four months have passed since SARS-CoV2, the etiologic agent of COVID-19, was initially reported in Wuhan, China in the first week of December 2019. It was officially brought to the government attention at the end of December, and upon evaluation by several teams of experts, it was recognized by the Chinese government as a new virus-borne disease in the third week of January 2020. The WHO announced it as a PHEIC (Public Health Emergency of International Concern) on 30 January 2020, and finally a global pandemic on 11 March 2020 [1]. Hua and Shaw (2020) provided a summary of the responses adopted in China in the first three months of the epidemic [2], while Shaw et al. (2020) provided insights on the initial responses followed in East Asia, focusing on China, Korea, and Japan [3]. The global chronologic status up to March 2020 has also been discussed [3].

The epidemiology of COVID-19 is constantly changing, and therefore, it is difficult to estimate an accurate disease incidence. In fact, 193 out of the 195 world countries have reported COVID-19 cases, and the number of affected people has soared to more than 7.2 million with more than 407,000 deaths as of 9th of June 2020 [4]. The hotspots of the disease have constantly changed: from China, it initially shifted to Iran, Italy, and South Korea, and then moved to other parts of Europe such as Spain, France, and the UK. The hotspot then changed to the USA, with the largest number of infected 
people and casualties. New hotspots are more recently found in Brazil and Russia with the second and third highest numbers of infected people. In particular, the case of Brazil is alarming in the sense that the daily new cases are rising in the range of 20,000 to 30,000. Recently, the Brazilian government has decided to change the reporting system, and exclude the accumulated counts. Russia, which currently has the third-highest global number of infected individuals has a presumably questionable low death rate (often termed as unreported death cases). Moreover, a new hotspot seems to be emerging in India, a country with a large population density, especially in the informal settlements. Altogether, this makes COVID-19 the worst pandemic in the modern age, after the Spanish flu, which occurred more than 100 years ago.

Shaw et al. (2020) pointed out that SARS-CoV2 (and COVID-19) has the following characteristics: (1) a high spread rate (and speed), (2) affects more severely the aged and immunocompromised people (the most vulnerable), and (3) is associated with differential recovery rates in different countries and age groups [3]. Although in most countries, the vulnerable populations are those above 65 and/or 70 years of age, the younger population, including those in their 20s, 30s, and 40s, are also affected. There are also many cases of asymptomatic infection, where an individual has not developed any COVID-19 symptoms but tested positive for the virus, potentially making COVID-19 (and its transmission) even more complicated. Thus, widespread testing is considered an important tool to detect affected people in most countries, followed by quarantine, physical distancing, and lockdowns, among others.

It should be noted that while the pandemic is global, the responses are local [3]. The specific response against COVID-19 depends on the country's governance system, regulations/ constitutional provision, capacity, the robustness of its health system, and, more importantly, culture and citizens' behavior. Therefore, every country has its own unique success/failure story, depending on its own local conditions. Even within one country, local governments (at state, province, or prefecture levels) have their own unique response mechanisms. Shaw et al. (2020) mentioned the importance of a multi-disciplinary approach to the COVID-19 response [3].

This study was not based on "pure epidemiological analyses". Rather, we attempted to understand the policy and behavioral responses in Japan, locating them in the COVID-19 timeline, as well as the implication of the emergency announcements in the country. For a detailed analysis of government action, we refer to earlier publications [3]. The core part of the paper provides an analysis of the inherent socio-political system in Japan, along with its people's behavior and immune status. An attempt was also made to highlight the ecosystem-based approach as a potential future lifestyle. This paper is intended for a wider audience who work in the environment, disaster, and development fields, particularly those who study possible ways to address biological hazards. We need to emphasize that the results are not supposed to be compared with how the other countries flattened their curves. We all understand that the "pandemic is global and its responses are local". So, keeping in mind the local response issues, this paper demonstrates the example of Japan.

\section{History of COVID-19 in Japan and Basic Policies and Measures Applied}

The first case of COVID-19 was reported in Japan between January 10 and 15, 2020: a Chinese national who traveled to Wuhan. The proximity of Japan to China, the high travel volumes between the two countries, the high percentage of aged individuals in Japan, a high population density in urban metropolitan areas such as Tokyo and Osaka, and high volumes of commuters in these major cities made Japan especially vulnerable to this pandemic (in theory). However, in spite of these vulnerabilities and the expected higher exposure rates, the country has been able to suppress the initial spread of the disease by flattening the curve and reducing the number of contagions and deaths.

Figure 1 shows the basic concept of Japan's response to COVID-19 [5-7]. While most of the countries experienced high increases in the number of affected people and fatalities, Japan has been able to limit its initial outburst. As of 7 June 2020, Japan had reported more than 17,000 cases, of which 910 individuals died [5]. Although some criticize and point out that Japan has not done enough testing, and that the number of infected cases may be higher than the officially reported, the death statistics 
confirm the initial flattening of the curve. In this section, some key countermeasures adopted in Japan are discussed within the respective timeline.

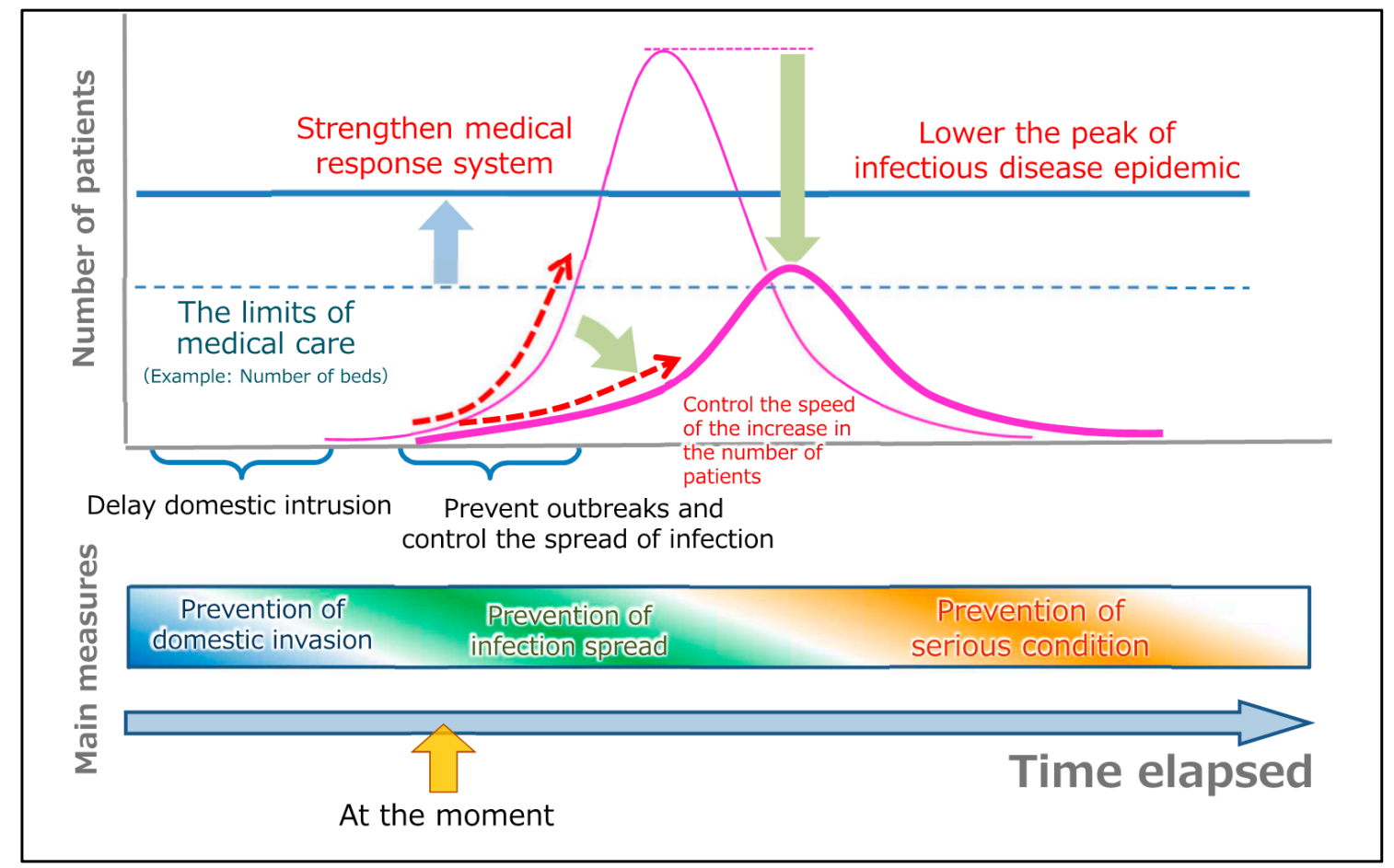

Figure 1. Illustration of Japan' COVID-19 response (source: [6,7]).

Shaw et al. (2020) [3] and Wiki (2020) [8] provided analytical overviews of the responses and key approaches adopted in Japan, such as border control measures (Mizugiwa Taisaku in Japanese), a cluster approach, an expert committee's scenario planning, and overshooting challenges, among others. Three main potential phases were considered in these approaches: (1) prevention of domestic spread, (2) prevention of the spread of infection, and (3) prevention of serious spread. It seems that Japan is currently in the third phase, which aims to prevent serious illness from occurring. The key target of this approach was to reduce the number of affected people by lowering the peak and strengthening the medical system. This is crucial to prevent outbreaks and control the speed of infection, so as to provide enough time for the medical facilities to be prepared. This was done by strengthening other countermeasures such as border control, identifying key clusters, closing schools, promoting telework, and avoiding large public gatherings (e.g. cancel key sports events and festivals such as the cherry blossoms' viewing). To maximize the efforts to suppress transmission and minimize socio-economic damage, the following three steps were taken:

(1) early detection of and early response to clusters, (2) enhancement of intensive care responses via securing medical service systems for severely ill patients, including medical equipment (Ventilator, ECMO, etc.), and (3) enforcement of citizens' behavioral modification [7].

Japan focused mainly on detecting and control the clusters of infection and performed selective testing for the virus, under the rationale that to end the epidemic quickly, it was extremely important to prevent one cluster from developing into another cluster. It was also important to curtail the rate of increase of cases (and patients) as much as possible through these preventive measures, in order to control the epidemic in Japan [7]. This was effective at an early stage, however, in the longer run, it failed to prevent the disease spreading. One-third of Tokyo's cases in late March and early April were linked to sports clubs, pubs, and other night entertainment establishments, where cluster tracing is difficult [9]. However, this gradually decreased with the announcement of a national emergency, which we better describe in the next section. Meanwhile, compliance with calls for remote working and 
social distancing has been weak. In fact, it is argued that many Japanese companies were not equipped (and prepared) to adopt remote working schemes. Furthermore, the relatively smaller houses in urban areas, where the space to work is limited was also a condition. Moreover, public transportation operated as normal, although certain routes have reduced their number of trains or buses.

As for immigration restrictions, Japan's response was slow. The US, the Philippines, Singapore, Indonesia, Vietnam, and Taipei adopted quarantine measures that were implemented soon after Wuhan was locked down, from 23 January 2020 [10]. Travelers who visited Wuhan within the past 14 days were prohibited from entering these countries. On the opposing side, at that time, Thailand and Cambodia did not restrict immigration. In contrast, in Japan, the government took a weak measure and prohibited the entry of people who had stayed in Hubei, China in the last 14 days (from 1 February 2020). The government also prohibited the entry of people coming from 73 countries/regions in the 2 April 2020 [11].

Figure 2 provides a timeline analysis of Japan's response to COVID-19. Japan's response can be divided into five major phases: (1) the containment phase, (2) the medical service reinforcement phase, (3) the mitigation phase, (4) the emergency phase, and (5) the recovery phase. Each phase is characterized by certain policy measures. During the containment phase in January 2020, the key focus was to reduce the number of visitors from the key affected areas in China, including Wuhan. Immediately after China declared the new virus and the WHO's announced COVID-19 as a public health emergency of international concern (PHEIC), Prime Minister Abe announced COVID-19 as an infectious disease under the Infectious Disease Control Law on 28 January 2020, and a COVID-19 headquarters was established in the Prime Minister's Office on 30 January 2020, including senior bureaucrats from different key ministries. In addition, during this phase, the luxury cruise ship Diamond Princess docked in the Yokohama harbor, and several new COVID-19 cases were reported. The initial decision-making and response of the COVID-19 headquarters focused on managing patients on the Diamond Princess as well as developing strategies to reduce the disease spread in the country.

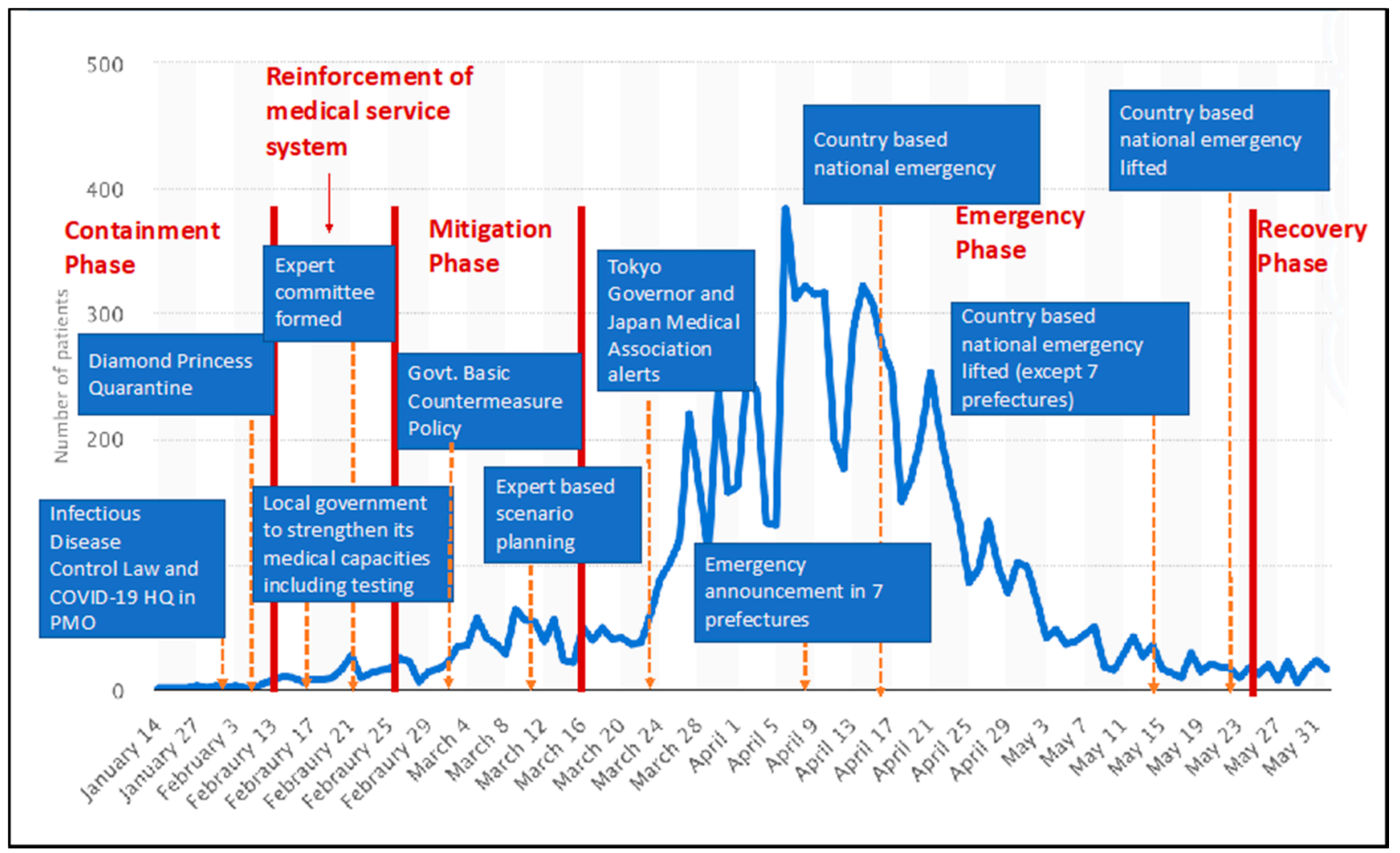

Figure 2. Timeline of the COVID-19 response in Japan with the specific policy measures adopted (source: authors based on data from [12]). 
The analysis of the number of secondary transmissions caused by a single infected person, based on the relevant cases, revealed that the number of secondary transmissions was significant in cases where the root of infection was a closed space with poor ventilation [7]. During the following phase (medical service reinforcement phase), mainly in February 2020, the emphasis was placed on the strengthening of the medical care system. Local governments were instructed to strengthen their medical capacity and to increase the testing capacity. On 16 February 2020, the Ministry of Health, Labor, and Welfare worked with local governments to establish 536 consultation centers that covered every prefecture within the country to provide concerned citizens with instructions on how to get tested for COVID-19 and receive treatment, if needed.

Not long after, Prime Minister Abe convened the government's first Novel Coronavirus Expert Committee Meeting at the Prime Minister's Office to draft the national guidelines for COVID-19 testing and treatment. The expert committee brought together ten public health experts, medical professionals, and data scientists from across Japan to coordinate a response to the virus with Abe and the government's coronavirus task force in a roundtable format.

The mitigation phase started with the establishment of the Basic Countermeasure Policy for COVID-19 on 25 February 2020, based on suggestions from the expert committee. On 27 February 2020, Prime Minister Abe requested the closure of all schools from 2 March 2020 until the end of spring break, in early April. The next day, the Japanese government announced plans to create a fund to help companies subsidize workers who needed to take time off to look after their children. On 27 February 2020, the Japanese government announced plans to expand the national health insurance system so that it would cover COVID-19 testing. The key characteristic of this phase was the close cooperation of the expert committee and government decision-making. The expert committee developed detailed scenarios with different levels of uncertainties and calculated the required percentage of physical distancing. Data science played an important role in these models. These scenarios were used to design specific mitigation measures. One of the difficulties of COVID-19 response in Japan is the approximate 12-day delay between the diagnosis and its registration in the official statistics [6]. Therefore, for better accuracy, human mobility via mobile phone data as an early indicator of confirmed cases was also explored [13]. For instance, NTT DoCoMo data and high-resolution hourly population data of Mobile Kukan Toukei within Tokyo were analyzed [13]. The dataset divided Tokyo into 8500 grid cells of $0.5 \mathrm{~km} \times 0.5 \mathrm{~km}$. The preliminary analysis suggested that the mobility levels correlated with the daily growth rate of confirmed cases within the following 12 days. On 9 March 2020, the Health Ministry published a disease forecast for each prefecture and instructed their local governments to prepare their hospitals to accommodate the estimated patient numbers. Furthermore, it was predicted that the virus peak in certain prefectures (such as Tokyo, Osaka, and Hokkaido) would occur three months after their first reported case of local transmission.

In the next phase (Emergency Phase), to provide a stronger legal basis for COVID-19 countermeasures, the National Diet passed an amendment to the "Special Measures Act to Counter New Types of Influenza of 2012" on March 13. The new act allows the Prime Minister to declare a "state of emergency" in specific areas where COVID-19 poses a grave threat to the lives (and economic status) of residents. On 30 March 2020, the Tokyo Governor requested its residents to stay at home for the next two weeks. The Japan Medical Association, in a press conference, expressed their concern on the current infection spread rate and advised the Prime Minister to declare a national emergency. On April 7, Prime Minister Abe called for a national emergency for one month in the seven most affected provinces effective from 8 April 2020. The national emergency was later extended to cover all of Japan on 16 April 2020. On May 14, the emergency phase was over in most prefectures (except in Tokyo, Kanagawa, Saitama, Hokkaido, Osaka, Hyogo, and Kyoto). Finally, on 25 May 2020, the national emergency was lifted in the whole country.

From all of the abovementioned, the key points of Japan's policy responses are [7]: (1) provision and sharing of information (call for self-restraint on travel and going out), (2) surveillance and information gathering (identifying carriers, strengthening testing systems, and continuing to develop 
rapid test kits), (3) pandemic prevention (declaration of the state of emergency, and its extension), (4) medical care (3C approach (closed space, crowded space, closed contact setting) and PCR testing),

(5) economic and employment measures (new fiscal boosting), (6) other important considerations (procurement of essential goods, give relevance to social functions, preventing core government staffs from being infected). In the recovery phase, there has been a very strong focus by the government on the economy. A fiscal stimulus package, of 108.4 trillion Japanese Yen ((1.01 trillion USD), which is equivalent to $20 \%$ of the national GDP, was approved. Furthermore, there was a supplementary addition of 16.8 trillion JPY, which brought the total package to 117.1 trillion JPY.

\section{Emergency Law in Japan and its Implications}

Japan's emergency law is unique and different from that of other countries. The law does not allow the government (national or local) to enforce lockdowns. However, the head of the government (Prime Minister and governors) can appeal to the people to stay at home and request stores and other high-risk facilities to close. There is a delicate line of power between "request" (Yosei in Japanese) and "demand"' (Kyosei in Japanese). The 3C approach (closed space: Mippei in Japanese; Crowded space: Misshu in Japanese; Close contact setting: Misshu in Japanese) was (and is) emphasized during the emergency period. This means that people need to follow stay at home orders, avoid crowded places, and avoid close contacts.

During emergency periods, governors of the affected areas will receive the following powers: (1) instruct residents to avoid unnecessary outings unless they are workers in essential services such as healthcare and public transportation; (2) restrict the use of or request the temporary closure of businesses and facilities, including schools, social welfare facilities, theaters, music venues, and sports stadiums; (3) expropriate private land and buildings for the purpose of erecting new hospitals; and (4) requisition of medical supplies and food from companies that refuse to sell them, punish those that hoard or do not comply, and force firms to help transport emergency goods. These powers enable governors to take certain legislative actions. Mayors as well as town and village heads, have less autonomy but can appeal to the prefectural governor who can then make final decisions. For instance, in order to secure adequate supplies of medicine and other necessary goods, governors can fine uncooperative businesses involved in their distribution. Prefectures can also appropriate land and buildings for use as temporary medical facilities without the agreement of the owners, if necessary. Furthermore, the governors' non-legislative initiatives can include strongly urging people to avoid unnecessary travel as well as crowded spaces such as bars, nightclubs, restaurants, and karaoke boxes, pressing for sports and cultural events to be postponed or canceled, and asking people to refrain from using school facilities.

Thus, in Japan, a forced lockdown is not possible by law. Therefore, people's behavior and self-consciousness are extremely important for the flattening of the COVID-19 curve. During an emergency, repeated requests from governors, ministers, and the prime minister as well as experts' advice, are conveyed through the media sources. This has a large impact on people's behavior. At the local level, citizen/voluntary organizations played an important role in raising awareness for maintaining "social distancing"' and avoiding crowded areas. In addition, after the national emergency was lifted in the third week of May, some of the local governments remained vigilant and prepared to act quickly. For instance, the Tokyo Metropolitan Government, issued Tokyo alerts whenever the number of new affected cases reached double-digits (24, 22, 18 in three consecutive days), and interdicted (using red-colored symbols) Tokyo venues such as the city hall and the rainbow bridge. Additionally, other local governments such as the one from Kitakyushu city alerted its residents and requested the care for self-restraint, whenever new cases in the range of double-digits were reported on consecutive days in the city.

We believe that the governance and policy actions followed in Japan should be looked at and can be adopted in other countries, especially with respect to science-based decision making. 


\section{Characteristics of Japanese Lifestyles and Their Possible Implications}

In this section, we argue that a combination of factors such as Japan's basic health policy, people's health consciousness and basic sanitation practices, food habits, and immune statuses enabled the flattening of the COVID-19 curve, ultimately reducing the number of resulting deaths. Although Japan has not conducted extensive coronavirus testing in comparison to other countries, we discuss the reasons for this decision, describing several hidden and unique aspects of this particular country.

\subsection{Culture}

Japan has a different greeting culture from other countries, and social distancing is normal. Maintaining good social distancing, including avoiding groups of people and maintaining a physical distance from strangers, may help prevent infections from spreading. Unlike Western countries, the Japanese do not have the custom of kissing on the cheek or hugging as a greeting. The Japanese hardly make any physical contact with friends or family while greeting them. Japan holds social isolation practices, even in densely urbanized areas [14]. As for greetings, Japanese often bow and sometimes shake hands. Thus, the country's culture is geared around maintaining a personal space [15].

Furthermore, Japanese people who are sick with cold, flu, or allergies normally wear surgical masks in public to prevent others from getting sick. This behavior is based on the "Japanese collectivism" in comparison to the "American individualism" [16]. Therefore, Japanese people do not have emotional resistance to wearing masks, whereas people in other countries are reluctant to wear them daily. Although recent psychological studies suggest that the theory is not applicable to young Japanese people [17], this tendency does not directly reflect the COVID-19 response. However, the number of infections under 40 years of age is increasing owing to unnecessary night outings. The only approach to tackle this issue was the closure of night clubs, bars, and restaurants enforced by prefectural governors in the context of a national emergency. Of note, the government provided economic compensation based on the size of the business affected. Moreover, most of the restaurants in the residential neighborhoods started "take-out" systems instead of serving the meals in the restaurant.

In contrast, some young Japanese citizens also cooperate, but based on self-interest [18]. In these cases, the behavior of wearing masks is based on not contracting the cold or flu virus from others. Regardless of whether their behavior is based on collectivism or self-interest, the more important message here is that wearing a mask can also signal others to keep their distance.

\subsection{Healthcare System}

Japan has a prominent health care system that provides universal health coverage. Japan has introduced the National Health Insurance (NHI) system in 1961. The NHI ensures that all citizens are provided with essential healthcare, regardless of preexisting conditions or economic status; free access, meaning patients are free to choose any hospital nationwide; and high-level care at low cost since the system is maintained with the use of public money [19]. In Japan, patients usually receive a plethora of tests when treated for even nonserious health problems, which are covered by the NHI. According to Japanese criteria for COVID-19 [20], if a person has any of the following symptoms they should first contact a coronavirus consultation center:

(1) Cold symptoms and/or a fever above $37.5^{\circ} \mathrm{C}$, which lasts for 4 days or more,

(2) Elderly or those with preexisting health problems,

(3) Heavy physical fatigue or trouble breathing.

As for the number of tests (and confirmed infected individuals) in Japan, Japan has run so few tests because the Ministry of Health, Labor and Welfare initially chose PCR (polymerase chain reaction) testing not as a "medical procedure," but as a tool for "epidemiological investigation" to curb the outbreak spread [20]. As per the regulation, when a condition is under epidemiological investigation, it cannot be covered by the NHI; however, later when PCR was included as a medical procedure, it was possible to use the NHI. The expert panel advising the government mentioned that the "overwhelming" 
shortage of personal protective equipment for sample collectors and laboratory technicians has been one of the factors behind a slow pickup in PCR tests. However, as of 10 May 2020, the permission process is complete to start immune-based tests, which are simpler and quicker to conduct than PCR tests.

On the other hand, Chest CT is used for the diagnosis of COVID-19 (before PCR testing) although lung ultrasound rivals $\mathrm{CT}$ imaging for fast and accurate bedside diagnosis and monitoring of coronavirus infection. Ai et al. (2020) suggested that chest CT has a high sensitivity for the diagnosis of COVID-19 [21]. The stocked number of CTs in Japan is 107.2. million, and the average of OECD is $25.4 /$ million. Thus, Japan probably conducts four times more Chest CT per patient than in other countries. As a result, the number of PCR tests related to COVID-19 was lower.

\subsection{Sanitation}

UNICEF highlighted the importance of handwashing as a preventive measure for COVID-19. Japan is the world's largest donor in the water and sanitation sector based on its experience, knowledge, and technology [22]. In Japan, the Ministry of the Land, Infrastructures, Transport, and Tourism (MLIT) manages offsite sanitation (sewerage and wastewater management), while the Ministry of the Environment (MOE) manages on-site sanitation (johkasou, septage management with scheduled desludging, and sludge treatment facilities) [23]. Owing to such technical achievements in sanitation, people can easily access clean water and drinking water. In addition, as for the individual behavioral level, the Japanese have educated handwashing with soap habits in their homes and schools since a tender age, and all people living in Japan have easy access to soap [24]. In this custom, the Japanese wash their hands after going to the toilet, returning home, meals, etc. According to a survey of the MHLW, $85.6 \%$ of respondents answered that they wash hands, gargle, or use hand sanitizer for coronavirus prevention [25]. In contrast, according to UNICEF, in the world, $40 \%$ of people (about 3 billion) do not have basic handwashing facilities at home. Moreover, over one-third of primary schools in the world (over half in developing countries) do not have handwashing facilities for children [24].

In Japan, not only soap but also hand sanitizers, ant-bacterial sprays, and rubbing alcohol are popular. They are set up everywhere, such as in front of the entrance of a building and near the bathrooms. Another sanitation behavior is the regular gargling of the throat. In other countries, it is considered a vulgar behavior, and there has never been any custom of doing it. In contrast, gargling is commonly seen in Japan as a helpful habit to prevent sickness. The custom of gargling to prevent sickness goes back centuries to the Heian Period, which lasted from 794 to 1185 [26]. In Japan, gargling is considered one of the two common-sense ways of not getting sick during the winter, along with washing hands. Satomura et al. (2005) showed that simple water gargling is effective in preventing upper respiratory tract infections [27]. This virtually cost-free modality would appreciably benefit the general population and contribute to reducing the risk of infection.

\subsection{Food Habits}

During meals, the Japanese do not usually eat by hand, but often use chopsticks. People in western countries also use knives, spoons, and forks, but they frequently use their hands, particularly when eating junk food (hamburger, sandwich, pizza, etc.). Eating by hand without washing hands increases the risk of infection. There are many fast-food chains in Japan, but most of the shops and restaurants serve hot wet towels with meals, and people can easily wipe their hands. It is a unique Japanese custom.

As for food habits, the Japanese prefer a traditional dish style of one soup and two side dishes served in small plates, compared with meat-oriented diets in western countries. These side dishes play an equal role as the main dish in providing sustenance and making the meal more appetizing. For side dishes, fermented foods are often used (such as soybeans (e.g., miso, soy source, natto), Japanese sake, and pickles). Fermented foods contribute to improved immune system function, prevent intestinal afflictions, and promote good health via the maintenance of a well-balanced gut microbiota 
composition [28]. In this sense, many traditional Japanese foods are filled with antioxidants, vitamins, minerals, and even beneficial bacteria. For example, miso is a fermented soybean paste that is a culinary pillar in Japanese food flavoring. Miso is a great source of probiotics or beneficial bacteria, which increases the health of the gut and enhances the immune system by providing high protein and mineral amounts, such as manganese zinc, vitamin E, vitamin $K$, various B vitamins, and folic acid [29]. Natto was also reported to contribute to healthy gut flora [29]. Furthermore, bacteria in Japanese pickles were shown to boost the immune system and prevent flu [29]. Matcha was consumed in Japan long before it was a trending latte flavor-it was first introduced from China by a Japanese Buddhist monk in 1191 [29]. Matcha is packed with antioxidants up to 137 times more than other types of green tea, which helps to reduce cell damage and fight chronic diseases [29]. In addition, seaweeds (e.g., nori, wakame, and aosa) affect bacterial infections [30]. In fact, edible seaweeds were reported to have an active principle which may help to defeat COVID-19 [31]. Drinking matcha may also help protect against heart disease by lowering "bad" cholesterol and increasing metabolism.

The Centers for Disease Control and Prevention (CDC) mentioned that the deterioration of the immune system by chronic health conditions, especially in the elderly, complicates coronavirus infections [32]. Although there is no evidence that attests to the effect of fermented foods on COVID-19, taking fermented foods impacts our guts and promotes health.

\subsection{Immune System}

Coronavirus has mutated into two strains, the "S-type"' is older and appears to be milder and less infectious, while the "L-type", which emerged later, spreads quickly and currently accounts for around $70 \%$ of cases [33]. Japan did not strictly restrict travelers from China during the first outbreak. As a result, the new infections caused by the "S-type" coronavirus spread first in Japan. Fortunately, this expansion may have been important to confer a degree of collective immunity against the "L-type" coronavirus that emerged later [34]. Although there are controversies, this relates to inherent immunity statuses, as per some scholars [35]. Nishijima et al. (2016) found that the composition of the Japanese gut microbiome contains greater Actinobacteria, particularly Bifidobacterium [35]. They also found that while there are a large number of carbohydrate metabolism microbial functions, there are few related to replication, repair, and cell motility. The analysis also showed that hydrogen, primarily used for methane generation in individuals from other countries, is primarily used for acetic acid generation in Japanese individuals. The enzyme responsible for the hydrolysis of polysaccharides in nori and wakame (edible seaweeds) was found in approximately $90 \%$ of Japanese individuals as opposed to $15 \%$ and under of individuals from other countries [35]. These findings suggest that the beneficial traits of Japanese people's gut microbiomes may condition potential resistance to infections. This evidence may explain why the number of Japanese COVID-19 cases is rather low. Table 1 summarizes six aspects of Japan's uniqueness making a parallel to overseas contexts. 
Table 1. Six aspects of Japanese uniqueness (versus overseas).

\begin{tabular}{ccc}
\hline Aspect / Factors & Japan & Overseas \\
\hline Lockdown & 1. Government Response & Yes \\
\hline Immigration restrictions & $\begin{array}{c}\text { No, but declared a state of emergency for seven } \\
\text { prefectures that then evolved to a nationwide } \\
\text { emergency state }\end{array}$ & Yes \\
\hline Remote work & Yes & Applied \\
\hline Closing schools & Applied & Applied \\
\hline Greeting & Applied & \\
\hline Social distancing & 2. Culture & Shake hands, hug, Cheek kissing \\
\hline
\end{tabular}

No emotional resistance

$\begin{array}{llll}\text { Wearing a mask } & - & \text { affected person } & \text { Emotional resistance }\end{array}$

\begin{tabular}{|c|c|c|}
\hline \multicolumn{3}{|c|}{ 3. Health Care System } \\
\hline $\begin{array}{l}\text { National Health Insurance } \\
\text { Program }\end{array}$ & Universal (for all people) & Regional disparities \\
\hline $\begin{array}{l}\text { Medical system (guideline for } \\
\text { COVID-19, CT scan, etc.) }\end{array}$ & Available with detailed guidelines & Available \\
\hline PCR & After CT scan & Following diagnosis \\
\hline No. of CT [36] & 107/million & OECD: 25/million \\
\hline \multicolumn{3}{|c|}{ 4. Sanitation } \\
\hline Basic handwashing with soap & $\begin{array}{l}\text { Educated since childhood } \\
\text { Frequent }\end{array}$ & $\begin{array}{l}\text { Regional disparities } \\
\text { Washing hands after toilet [37]: } \\
\text { Italy } 57 \% \text {, UK } 75 \%\end{array}$ \\
\hline Gargling throat & Educated since childhood & Not common \\
\hline Hot water bathing & $\begin{array}{c}\text { Japanese custom } \\
\text { Almost all houses have a bathtub }\end{array}$ & Shower instead of immersion bath \\
\hline Ventilating a room & Open window & Air conditioner \\
\hline Disinfection gel & At the entrance of a building or in a washroom & Regional disparities \\
\hline Wet towel & Served when eating out & Served rarely \\
\hline \multicolumn{3}{|c|}{ 5. Food Habits } \\
\hline Eat seaweeds & Yes (marine algae, marine plants) & Rarely \\
\hline Eat fermented food & $\begin{array}{l}\text { Yes (miso, soy source, tsukemono) } \\
\text { something that includes lactic acid bacteria) }\end{array}$ & $\begin{array}{l}\text { Few (e.g., yogurt, cheese, beer, } \\
\text { wine) but a different type of } \\
\text { Japanese foods }\end{array}$ \\
\hline Cutlery & Chopsticks & $\begin{array}{l}\text { Folk, knife, spoon, but sometimes } \\
\text { use hands }\end{array}$ \\
\hline \multicolumn{3}{|c|}{ 6. Immune System } \\
\hline Spread type of COVID-19 & $\begin{array}{l}\text { S-type spread from China earlier than L-type, } \\
\text { generating partial resistance }\end{array}$ & L-type spread \\
\hline Intestinal environment & $\begin{array}{l}\text { About } 90 \% \text { of Japanese have intestinal flora } \\
\text { with genes for enzymes that disassemble } \\
\text { dietary fiber in seaweed }\end{array}$ & $\begin{array}{c}\text { Less than } 15 \% \text { have genes found in } \\
\text { Japanese population }\end{array}$ \\
\hline Response measure & $\begin{array}{l}\text { Individuals take action to enhance their } \\
\text { immune system }\end{array}$ & $\begin{array}{l}\text { Depend on immunological } \\
\text { mechanisms of vaccination }\end{array}$ \\
\hline
\end{tabular}

\section{Discussion}

The COVID-19 outbreak reminds us of how an ecosystem-based lifestyle is important for modern people. Planetary and human health are not separable. Sustainable development, even in the context 
of an outbreak requires the integrated recognition that the environment and society are closely linked. There have been several arguments and discussions on ecosystem-based recovery, and how COVID-19 has urged us to become increasingly environmentally friendly. The economy recovery after COVID-19 should invest in nature, as a key focus. Within the framework of the Sustainable Markets Initiative under the leadership of His Royal Highness the Prince of Wales, a 10-point action plan to create a circular bioeconomy was proposed [38]. The 10-point actions include: (1) aim at sustainable wellbeing, (2) invest in nature and biodiversity, (3) ensure an equitable distribution of prosperity, (4) rethink holistic land, food, and health systems, (5) transform industrial sectors, (6) reimagine cities through ecological lenses, (7) create an enabling regulatory framework, (8) bring purposeful innovation to the investment and political agenda, (9) ensure access to finance and enhance risk-taking capacity, and (10) intensify and broaden research and education.

In Figure 3, the concept of the relationship between geo-, eco-, and socio-environment is illustrated comparing Japan and overseas contexts. Of note, this comparison does not intend to prove the superiority or inferiority of any country; it rather demonstrates two different sets of cultures, customs, habits, governance, etc. The concept of the earth has been dominated by Cartesian philosophy, where the typical phenomena include urban structures and gardens in cities. Modernization is generally based on the logic of logos, from Greek philosophy, whereas Asian philosophy is based on the logic of the lemma from Buddhism [38]. In Asia, including Japan, unprecedented disasters occur, and people have seen their society dominated by nature firsthand. Natural factors, as well as social factors, can cause disasters, and these two aspects are intertwined.

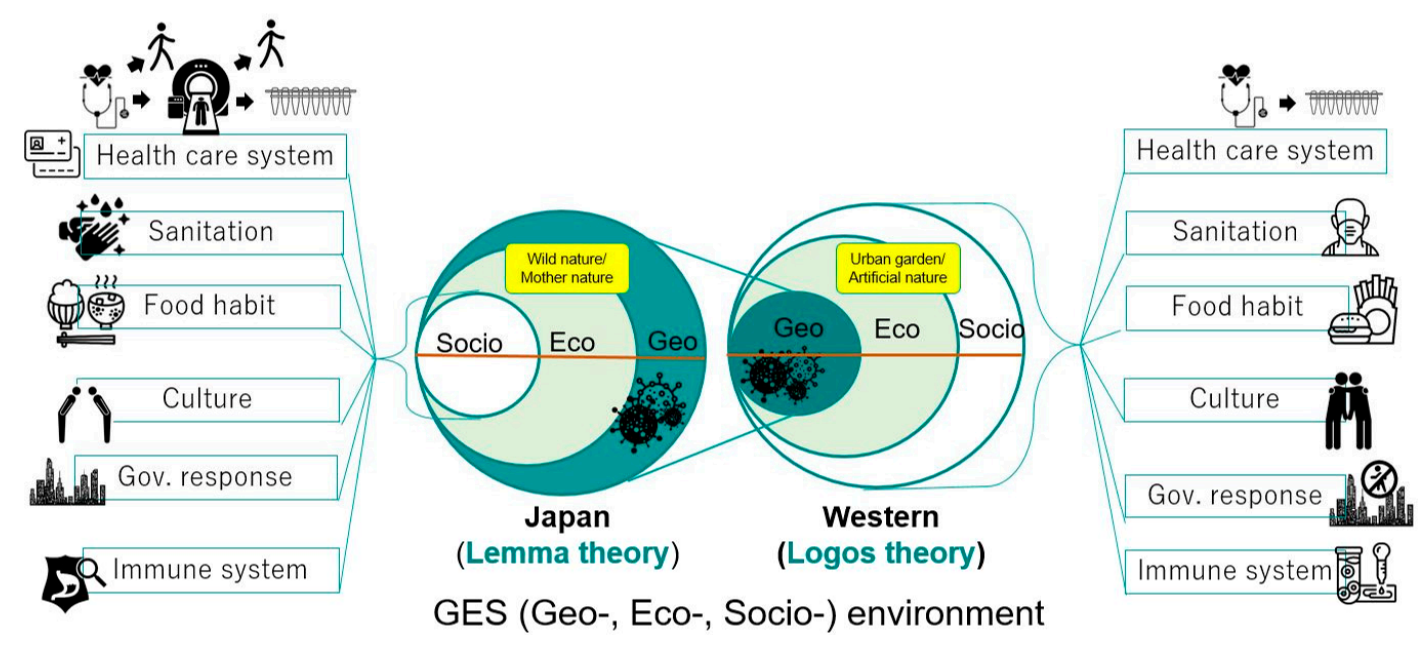

Figure 3. Relationship of the ges environment in Japan versus overseas countries.

The geo-environment has larger dimensions of climate change and natural disasters such as earthquakes, floods, droughts, and typhoons. The eco-environment governs the law of ecology (e.g., ecosystem services, functions, and services). The socio environment refers to the rules of society govern (e.g., human wellbeing) $[39,40]$.

According to Hagihara (2008), human wellbeing consists of three hierarchical levels in ecosystem health: the first level includes income, health, and a safe environment (e.g., lifeline, infrastructure, transportation, no pollution); the second level satisfies a convenient and comfortable environment (e.g., comfortable transportation, housing, green vegetation, and clean water); and the third level includes the realization of a meaningful life and fulfill communication, enjoying pastime and a flourishing natural environment (e.g., rich surrounding in close contact with community or relationship) [40].

The COVID-19 pandemic caused an unexpected shift in environmental health [41]. Owing to less traffic, decreased tourism, and industry shutdowns, polluted canals have transformed into waters clear enough to see fish swimming below in many countries [42]. Global air pollution has decreased after the outbreak owing to the lack of anthropogenic activities [42]. The International Union for 
Conservation of Nature (IUCN) has reported that COVID-19 could help save endangered species in China [43]. After the COVID-19 outbreak, many more people around the world have realized that many animal species have been adversely affected by humans [40]. COVID-19 may not be removed completely, it may appear again next year, and ultimately with the vaccine, it may become similar to other seasonal diseases such as influenza.

Madrodieva and Shaw (2020), in their analysis of Society 5.0 in Japan, have emphasized a human-centric society where technology connects people and tries to reduce the barrier of the digital divide [44]. Japan has taken steps towards developing definitions, principles, and standards for the focus areas of Society 5.0 and is considering proposing the devised standards to ISO to promote them in the international community. Healthcare and disaster prevention are the two key pillars of Society 5.0. It is envisaged that the futuristic society should focus on human and nature-centric approaches and policies while leveraging new technological innovations. In the case of Japan, we reviewed the current lifestyle and how actions were taken to shift from a modern lifestyle to a new optimal lifestyle, coping with the outbreak.

The successful integration of biological hazards into disaster risk reduction and response planning can be achieved if the following two goals are reached: (1) flattening the curve and enhancing the capacity of the healthcare system to achieve a better initial response; and (2) preventing and minimizing negative impacts on people (lives and livelihoods), socio-economic sectors, and development goals. Shaw et al. [45] in their recent review suggested ten steps for achieving these two goals. The ten steps are: (1) integrated surveillance and early identification and detection, (2) identification of hotspots/clusters at an early stage, (3) multi-disciplinary science-based decision support, (4) worst-case scenario planning, (5) inclusive (leave no one behind), human rights-based response and recovery planning, (6) trans-boundary and regional collaboration, (7) use of new and emerging technology, (8) public-private-people collective partnerships, (9) responsible media coverage and addressing fake news, and (10) transparency in information sharing. Japan's experience has shown the path for most of these steps for the initial response and the flattening of the curve. A successful recovery will depend on inclusiveness in recovery planning and transparency in sharing information in the future courses of action.

\section{Conclusion}

Although pandemics are global events, the responses to them are always local [3]. The purpose of this paper was not to compare the Japan case with those of other countries, but to highlight some of the key lessons that can be applicable to other countries where the infections are steadily growing. Shaw et al. (2020) have argued that governance, technological application, and citizen behaviors are some of the key aspects that could flatten the curves in China, Japan, and South Korea. This paper argues that, despite the close proximity to China, the high-volume of travelers between the two countries, a more aged population, and a high urban density, Japan has been able to flatten its curve initially. There are possibilities of second or third waves of infection in Japan, but at least the gap between the first and possibly forthcoming second wave has given the health care system enough time to prepare itself to adequately respond. From the study, it is evident that Japan has adopted a few important policies at the government level, which are supported by strong data and evidence-based analysis. The science-based decision/policy making was at the core of the government response. The other important part was a combination of five other factors: culture, health care system, sanitation, food habit, and immune status. Although these factors are very much Japan-related, the governance actions can be replicated in other parts of the world to cope with the pandemic.

To cope with future pandemic risks, we need to have the following:

(1) Robust integrated health and emergency management policy, the basic healthcare system should be a core pillar of society. During the pandemic response, an integrated emergency response system is required, where decisions are made based on science and expert advice, and adaptive policy responses are ensured. Chan and Shaw (2020) provided several cases of incorporating 
public health in disaster risk reduction [46] and vice versa through the health emergency disaster risk management framework (WHO 2019) [47-49].

(2) A healthy lifestyle is key to promote a healthy immune system. An ecosystem-based lifestyle change is essential, as exemplified above in the case of Japan. Mukherjee et al. (2020) argued for an ecosystem-based business continuity plan to recover from COVID-19.

(3) Use of new and emerging technologies: online classes, meetings, telework, etc. Extensive use of $5 \mathrm{G}$ and other information-related developments is essential [3]

(4) Being responsible and risk-aware citizens, employing a civic sense, and behavioral changes are core to any pandemic response [2,3].

Author Contributions: Conceptualization, R.S.; formal analysis, A.T., R.S.; writing—original draft, A.T. and R.S. All authors have read and agreed to the published version of the manuscript.

Funding: The authors received no specific funding for this work.

Conflicts of Interest: The authors declare no conflicts of interest.

\section{References}

1. WHO. COVID 10 Public Health Emergency of International Concern: Global Research and Innovation Forum; WHO: Geneva, Switzerland, 2020; p. 7.

2. Hua, J.; Shaw, R. Corona Virus (COVID-19) "Infodemic" and Emerging Issues through a Data Lens: The Case of China. Int. J. Environ. Res. Public Health 2020, 17, 2309. [CrossRef] [PubMed]

3. Shaw, R.; Kim, Y.K.; Hua, J. Governance, technology and citizen behavior in pandemic: Lessons from COVID-19 in East Asia. Prog. Disaster Sci. 2020. [CrossRef]

4. Nippon.com. Coronavirus Cases by Country. 2020. Available online: https://www.nippon.com/en/japandata/h00673/coronavirus-cases-by-country.html (accessed on 17 April 2020).

5. MHLW. Current Situation and MHLW Response to COVID-19. Ministry of Health, Labor, and Welfare (in Japanese). 2020. Available online: https://www.mhlw.go.jp/stf/newpage_10904.html (accessed on 17 April 2020).

6. MHLW. About coronavirus disease 2019. 2020. Available online: https://www.mhlw.go.jp/stf/seisakunitsuite/ bunya/newpage_00032.html (accessed on 15 April 2020).

7. PMO. Prime Minister Office of Government of Japan. 2020. Available online: http://japan.kantei.go.jp/ ongoingtopics/_00013.html (accessed on 15 April 2020).

8. Wiki. 2020 Coronavirus Pandemic in Japan. 2020. Available online: https://en.wikipedia.org/wiki/2020_ coronavirus_pandemic_in_Japan (accessed on 15 April 2020).

9. Rich, M.; Ueno, H. Japan's Virus Success has Puzzled the World. Is its Luck Running Out? The New York Times. 2020. Available online: https://www.nytimes.com/2020/03/26/world/asia/japan-coronavirus.html (accessed on 7 April 2020).

10. Mainichi Shimbun. State of Emergency for Tokyo and Six other Prefectures on April 7 To Ramp up Defenses against the Spread of the New Coronavirus. 2020. Available online: https://mainichi.jp/weekly/articles/ 20200417/wek/00m/040/002000c (accessed on 7 April 2020).

11. Mine, Y. "Immigration Restrictions" and "Isolation" Comparison of Japanese Governments and Japanese Responses against New Coronavirus. Yahoo Japan News. 2020. Available online: https://headlines.yahoo.co. jp/hl?a=20200224-00010003-wordleaf-pol\&p=1 (accessed on 7 April 2020).

12. New Cases of Coronavirus Disease (COVID-19) Confirmed by day in Japan from January 14 to June 12020. Available online: https:/www.statista.com/statistics/1105032/japan-new-confirmed-cases-of-coronavirus-byday/ (accessed on 7 June 2020).

13. Miyoshi, K.; Murayama, H. Mobility changes in Tokyo, The Global Data Science Project for COVID-19. 2020. Available online: https://www.covid19analytics.org/post/social-distancing (accessed on 10 May 2020).

14. Takeda, T.; Kamagahara, Y.; Lu, X.; Kida, N.; Hara, T.; Ota, T. Study of the difference in the movement of experienced and inexperienced persons in Japanese bowing. In Advances in Intelligent Systems and Computing; Springer: Cham, Switzerland, 2017. [CrossRef] 
15. ThePrint. Social Distancing is the Norm in Japan. That's why COVID-19 Spread is Slow there. The Print. 2020. Available online: https://theprint.in/health/social-distancing-is-the-norm-in-japan-thats-why-covid19-spread-is-slow-there/384498/ (accessed on 7 April 2020).

16. Imada, T. Cultural Narratives of Individualism and Collectivism: A Content Analysis of Textbook Stories in the United States and Japan. J. Cross-Cult. Psychol. 2012. [CrossRef]

17. Furuya, S. Reinterpretation of Japanese Collectivism: Based on "Self-Interested Cooperation." Global studies. Musashino Univ. Acad. Inst. Repositry. 2018. Available online: http://id.nii.ac.jp/1419/00000861/ (accessed on 7 April 2020).

18. Ishii, M.; Hamamoto, M.; Tsuruoka, H. JMA perspectives on the universal health insurance system in Japan. Jpn. Med Assoc. J. 2010, 53, 139-143.

19. Yano, H. Coronavirus: Why Japan tested so Few People. Retrieved 12 March 2020, from NIKKEI Asian Review. 2020. Available online: https://asia.nikkei.com/Spotlight/Coronavirus/Coronavirus-Why-Japantested-so-few-people (accessed on 7 April 2020).

20. Information for Public. Q \& A on Coronavirus Disease 2019 (COVID-19). Ministry of Health, Labor and Welfare. 2020. Available online: https://www.mhlw.go.jp/stf/seisakunitsuite/bunya/kenkou_iryou/dengue_fever_qa_ 00014.html (accessed on 7 April 2020).

21. Ai, T.; Yang, Z.; Hou, H.; Zhan, C.; Chen, C.; Lv, W.; Xia, L. Correlation of Chest CT and RT-PCR Testing in Coronavirus Disease 2019 (COVID-19) in China: A Report of 1014 Cases. Radiology 2020. [CrossRef] [PubMed]

22. UNICEF. Everything You need to Know about Washing your Hands to Protect against Coronavirus (COVID-19). Retrieved April 7, 2020, from UNICEF website. Available online: https://www.unicef.org/georgia/stories/everything-you-need-know-about-washing-your-handsprotect-against-coronavirus-covid-19 (accessed on 7 April 2020).

23. Asia Development Bank. Sanitation and Sustainable Development in Asia. 2016. Available online: https://www.adb.org/sites/default/files/publication/209511/sanitation-sustainable-dev-japan.pdf (accessed on 3 April 2020).

24. UNICEF. Handwashing with Soap, Critical in the Fight against Coronavirus, is 'out of reach' for Billions-UNICEF. 2020. Available online: https://www.unicef.org/eap/press-releases/handwashing-soapcritical-fight-against-coronavirus-out-reach-billions-unicef (accessed on 7 April 2020).

25. MHLW. The Results of the 1st "National Survey for New Corona Countermeasures" and Announcement of the 3rd "National Survey for New Corona Countermeasures." Ministry of Health, Labor, and Welfare (in Japanese). 2020. Available online: https://www.mhlw.go.jp/stf/newpage_10798.html (accessed on 7 April 2020).

26. Baseel, C. Gargling to Prevent Colds-Just a Japanese old Wives' Tale? JAPANTODAY. 2014. Available online: https://japantoday.com/category/features/health/gargling-to-prevent-colds-just-an-japanese-oldwives-tale (accessed on 7 April 2020).

27. Satomura, K.; Kitamura, T.; Kawamura, T.; Shimbo, T.; Watanabe, M.; Kamei, M.; Tamakoshi, A. Prevention of upper respiratory tract infections by gargling: A randomized trial. Am. J. Prev. Med. 2005. [CrossRef] [PubMed]

28. Bell, V.; Ferrão, J.; Pimentel, L.; Pintado, M.; Fernandes, T. One Health, Fermented Foods, and Gut Microbiota. Foods 2018, 195. [CrossRef] [PubMed]

29. Veld, E.V.T. 7 Japanese Superfoods to Boost your Immune System. 2020. Available online: https://japantoday. com/category/features/food/7-japanese-superfoods-to-boost-your-immune-system (accessed on 7 April 2020).

30. Déléris, P.; Nazih, H.; Bard, J.M. Seaweeds in Human Health. In Seaweed in Health and Disease Prevention; Academic Press: Cambridge, MA, USA, 2016. [CrossRef]

31. Wildish seaweed. Can Irish Seaweed help in the Fight against Viruses? 2020. Available online: https: //www.wildirishseaweeds.com/can-irish-seaweed-help-in-the-fight-against-viruses/ (accessed on 7 April 2020).

32. Nania, R. How Chronic Conditions Complicate Coronavirus Infections. AARP. 2020. Available online: https: //www.aarp.org/health/conditions-treatments/info-2020/chronic-conditions-coronavirus.html (accessed on 7 April 2020). 
33. Knapton, S. Coronavirus has Mutated into more Aggressive Disease, say Scientists. The Telegragh. 2020. Available online: https:/www.telegraph.co.uk/science/2020/03/04/coronavirus-has-mutated-aggressivedisease-say-scientists/ (accessed on 7 April 2020).

34. Kamikubo, Y.; Takahashi, A. Epidemiological Tools that Predict Partial Herd Immunity to SARS Coronavirus 2. MedRxiv 2020. [CrossRef]

35. Nishijima, S.; Suda, W.; Oshima, K.; Kim, S.W.; Hirose, Y.; Morita, H.; Hattori, M. The gut microbiome of healthy Japanese and its microbial and functional uniqueness. DNA Res. 2016. [CrossRef] [PubMed]

36. Kida, S. Image Diagnosis in Japan 2 -Comparison of CT and MRI Numbers and imaging Frequency with OECD Countries-. Imacel Academy. 2018. Available online: https://lp-tech.net/articles/8fix9 (accessed on 7 April 2020).

37. McCarthy, N. Where Europeans Wash Their Hands After Using The Toilet. Statista. 2020. Available online: https://www.statista.com/chart/4111/do-europeans-wash-their-hands-after-using-the-toilet/ (accessed on 7 April 2020).

38. Palahí, M.; Pantsar, M.; Costanza, M.; Kubiszewski, M.; Potočnik, J.; Stuchtey, M.; Bas, L. Investing in Nature to Transform the Post COVID-19 Economy: A 10-point Action Plan to create a circular bio-economy devoted to sustainable wellbeing. 2020. Available online: https://www.thesolutionsjournal.com/article/investing-nature-transform-post-covid-19-economy10-point-action-plan-create-circular-bioeconomy-devoted-sustainable-wellbeing/ (accessed on 9 June 2020).

39. Hagihara, Y.; Hagihara, K. Chapter 2 Water Resources Conflict Management: Social Risk Management. In Coping with Regional Vulnerability, New Frontiers in Regional Science: Asian Perspectives 4; Hagihara, K., Asahi, C., Eds.; Springer: Tokyo, Japan, 2016; pp. 21-41.

40. Hagihara, Y. Adaptive System Planning Methodology for Environmental Risk Management; Kyoto University Press: Kyoto, Japan, 2008. (In Japanese)

41. AFP BB News. The Cause of the Corona Pandemic is "Disrespect of Animals" Said by Mr. Goodall, a primatologist.. 2020. Available online: https://www.afpbb.com/articles/-/3278221 (accessed on 12 April 2020).

42. Jacobo, J. Venice Canals are Clear enough to see Fish as Coronavirus Halts Tourism in the City. abc NEWS. 2020. Available online: https://abcnews.go.com/International/venice-canals-clear-fish-coronavirus-haltstourism-city/story?id=69662690 (accessed on 17 April 2020).

43. Orjollet, S.; Christensen, S. VIDEO: Why Coronavirus could Help Save China's Endangered Species. CAPITAL NEWSPAPERS. 2020. Available online: https://capitalnewspapers.co.za/afp/938372/video-why-coronaviruscould-help-save-chinas-endangered-species (accessed on 17 April 2020).

44. Mavrodieva, A.; Shaw, R. Disaster and climate change issues in Japan's Society 5.0-A discussion. Sustainability 2020, 12, 1893. [CrossRef]

45. Shaw, R.; Chatterjee, R.; Dabral, A. Integrating Biological Hazards (including Pandemic) into Disaster Risk Reduction (DRR) Planning, Annex Document; UNDRR: Baltimore, MD, USA, 2020; p. 71.

46. Chan, E.; Shaw, R. Overview of health-EDRM and health issues in DRR: Practices and challenges. In Public Health and Disasters; Chan, E.Y.Y., Shaw, R., Eds.; Springer: Singapore, 2020; pp. 1-6.

47. WHO. Health Emergency and Disaster Risk Management Framework; WHO: Geneva, Switzerland, 2019.

48. DeWitt, A.; Djlante, R.; Shaw, R. Building holistic resilience: Tokyo's 2050 strategy. Asia Pac. J. 2020, 18, 1-5.

49. Djlante, R.; Shaw, R.; DeWit, A. Building resilience against biological hazards and pandemics: COVID-19 and its implications for the Sendai Framework. Prog. Disaster Sci. 2020. [CrossRef]

50. Mukherjee, M.; Chatterjee, R.; Khanna, B.K.; Dhillon, P.P.S.; Kumar, A.; Bajwa, S.; Shaw, R. Ecosystem-centric business continuity planning (Eco-centric BCP)- a post COVID19 new normal. Progress Disaster Sci. 2020. In press.

(C) 2020 by the authors. Licensee MDPI, Basel, Switzerland. This article is an open access article distributed under the terms and conditions of the Creative Commons Attribution (CC BY) license (http://creativecommons.org/licenses/by/4.0/). 